\title{
Article
}

\section{Failure investigation of layered LFT SB1plus package after bal- listic tests for level IIA}

\author{
Cătălin Pîrvu 1,2,*and Lorena Deleanu 2,* \\ 1 National Institute of Aerospace Research “Elie Carafoli” INCAS, Bucharest 061126, Romania \\ 2 Faculty of Engineering, "Dunărea de Jos" University of Galati, Galati 800008, Romania \\ * Correspondence: lorena.deleanu@ugal.ro (L.D.); pirvu.catalin@incas.ro (C.P.)
}

\begin{abstract}
The main objective of this study focuses on designing and testing body protection systems using advanced materials based on aramid fibers, for high impact speeds of up to $410 \ldots 430 \mathrm{~m} / \mathrm{s}$. The investigation of the failure mechanisms identifies issues of protective materials, major challenges and technological problems for efficient development of these systems. The authors presents an investigation on the failure processes and destructive stages of a ballistic package made of succesive layers of LFT SB1plus, taking into account the particular test conditions from NIJ Standard-0101.06 Ballistic Resistance of Body Armor. The main parameter of interest was the backface signature (BFS), but also details of projectile arrest and SEM investigaton could offer arguments in using this material for individual protection.
\end{abstract}

Keywords: aramid fibber; ballistic test; failure mechanism

\section{Introduction}

For hundreds of years, metallic materials have been used not only for body armor, but also for the protection of larger objects, such as vehicles, which is called "heavy protection." However, just a few decades ago, at the end of World War II, lighter solutions emerged, especially for military personnel, in the form of nylon ballistic vests. But those did not come close to the current level of ballistic protection offered by aramid fibers, yarns and fabrics, included in personal armors. Another advantage of ultra-fine polymer filament (not only aramid [1]) is that they offer extraordinarily flexible fabrics, which favors a high level of comfort for the wearer.

Ballistic applications of aramid fibers-based composites mostly include soft body armors. The mechanical properties of the aramids and the ballistic effects on its fabrics and composites have been investigated in several studies [2-5] that involved both experimental testing and FEM (Finite element method) [6-9] and established the effectiveness of the ballistic protecting system and the protection level of bulletproof vests. Recent reviews on ballistic protection [10,11], point out interesting comments on failure mechanisms and very particular solutions in combining different materials for facing very different threats. Research have been involving aramid fibers with different architectures, from simple or treated woven fabrics [12], to 3D fabrics [13] and unidirectional or multiaxial non-crimp fabrics, each solution being simulated with particular model conditions and tested for a specific threat, the conclusion of the documentation done by the authors being that each solution has to be experimentally investigated and the failure mechanisms to be understood in order to offer a design with very strong statistical reliability before using in the combat.

Bajya et al. [7] recently presented an experimental report on ballistic protection and failure mechanisms of soft armor packages, made of different structures, including woven and unidirectional fabrics. Packages made of para-aramid woven fabrics and unidirectional laminates, and hybrid ones were developed and subjected to ballistic impact against $9 \mathrm{~mm}$ lead core bullets, at an impact velocity of $430 \mathrm{~m} / \mathrm{s}$. Ballistic 
performance of each structure was evaluated in terms of back face signature (BFS), perforation ratio (PR) and expansion of bullet. The unidirectional aramid packages failed mainly due to fiber break, including fibrillation, debonding and delamination. The fiber orientation was only $\left(0^{\circ} / 90^{\circ}\right) \times 2$ and the surface density of this type of fabrics was 230 $\mathrm{g} / \mathrm{m}^{2}$, this inducing enough flexibility to allow for a too high BFS as compared to other solutions offered by these authors.

In general, ballistic threats are either from bullets or fragments. Bullets can be defined as projectiles of different shapes and consistencies, fired from weapons, such as pistols, revolvers and rifles. The fragments, on the other hand, may also result from explosions (for example, detonations of a grenade) or from the target the projectiles had already hit.

The various kinetic characteristics and deformation behaviors of such a wide range of bullets and fragments must require a customized study for each of this multitude of different projectiles and for the design required to face an impact process, in order to have an effective ballistic protection.

Even if nowadays, there were reported many models and simulations, from micro $[14,15]$, meso $[13,16]$, [ to macro $[17,18]$ scales, the tests remain the ultimate and restrictive step in adopting a certain type of individual armor, generally based on aramid fabrics.

An active field of research concerning the impact resistance of aramid fabrics has been involving the study of ballistic performance, from destructive investigation based on standard structures of packages [19] or structures involving new-entries like aerogels [20] and methodologies accepted by the interested parties. The standard structure of a ballistic package involves a certain number of layers of material or semi-finished product (as fabrics) for ballistic protection, which can vary within fairly wide limits between $8-40$ layers (or folds), depending on its architecture and the material characteristics for the ballistic protection.

The aim of this study is to evaluate a particular multiaxial fabric, LSF SB1plus, produced by Teijin [21] for designing body armors for the threat level IIA as classified in Ballistic Resistance of Personal Body Armor NIJ Standard-0101.04 [22], to identify failure mechanisms and to measure a well-accepted characteristic, backface signature (BFS) for the designed ballistic protection package.

\section{Material and testing campaign}

Even though fabrics based on aramid fibers are lightweight and offer a better protection, the designer will be forced to reduce the number of fabric layers required without compromising the effectiveness of the final protecting armor to reduce the cost. In general, aramid fibers are $43 \%$ lighter than glass fibers, as strong as E-Glass, ten times stronger than aluminum, close strength to carbon fibers (in tensile test). It also has good dimensional stability with a slightly negative coefficient of thermal expansion $\left(-2.4 \times 10^{-}\right.$ $6 /{ }^{\circ} \mathrm{C}$ ) and could resist chemicals with the exception of a few strong acids and alkalis. the aramids fiber exhibited an excellent stability over a wide range of temperatures for prolonged periods with no strength loss at temperatures as low as $-196{ }^{\circ} \mathrm{C}$ and do not melt but will start to carbonize at approximately $427^{\circ} \mathrm{C}[10]$.

The layers are available in the form of fabrics in unidirectional yarns (Figure 1), and can be combined into various structures and composites, each type having unique protection performance, forming ballistic packages with different uses, providing protection for a wide range of threats.

A recent tendency of research in trying to improve the response of aramid fabrics to ballistic impact is the 3D architecture [2], but fabrics with unidirectional layers with different angle orientation in sublayers is also intensively used for body armor, due to the fact that the strength of the yarns is not "consumed" in bending them in a 2D or 3D architecture. Of course, technology is obliged to find the adequate film and yarns for maintain these multi-axial orientations in a single layer. 


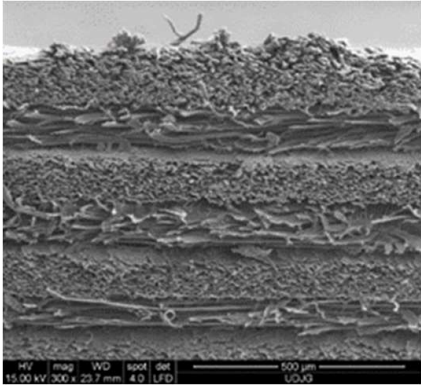

(a)

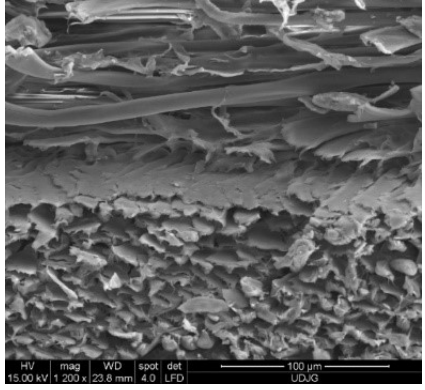

(b)

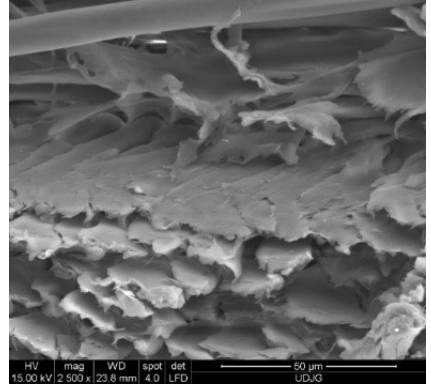

(c)

Figure 1. SEM images of the LFT SB1plus layers, after being cut by the help of a power guillotine. (a) magnification x300; (b) magnification x1200; (c) magnification x2500.

The architecture of the ballistic package is usually made of the same type of layer or combinations of two or more materials, the designer being interested in comparing ballistic packages with different numbers of layers in its structure [6]. For individual armor fabrics could be used as delivered, without adding adhesive among layers. No influence of stitching the layers on the ballistic resistance properties of the package was noticed.

Taking into account the stated criteria, the development of a type of soft armor, from the same aramid textile product, are quite numerous and technologically advantageous.

Designing a new individual protective armor request adequate layers and yarn arhitecture, taking into account the particular response of the system to particular threats and the protection degree, including here limitative request as acceptable value of backface signature (BFS).

The packages were obtained as successive layers of Twaron LFT SB1plus, as delivered in rolls by the producer, Teijin Aramid [21]. Twaron LFT SB1 plus is a fabrics of four layers of unidirectional Twaron yarns, with orientations $\left(0^{\circ}, 90^{\circ},+45^{\circ},-45^{\circ}\right)$, laminated together with a very small amount of polymer [21]. It has a surface density of $430 \mathrm{~g} / \mathrm{m}^{2}$ and the theoretical mass of the 12-layer package of $500 \mathrm{~mm}$ x $500 \mathrm{~mm}$ is $1290 \mathrm{~g}$. The manufacturing of the packages includes the cutting and coupling of the fabrics (in order to have a narrow variation of their weight), sewing and control. The package has the dimensions $500 \mathrm{~mm} \times 500 \mathrm{~mm}$, having an area of $0.25 \mathrm{~m}^{2}$, between recommended values by NIJ-C-4 $\left(0,23 \mathrm{~m}^{2}\right)$ and NIJ-C-5 $\left(0,3 \mathrm{~m}^{2}\right)$ for high and very high surfaces (Figure 2$)$.

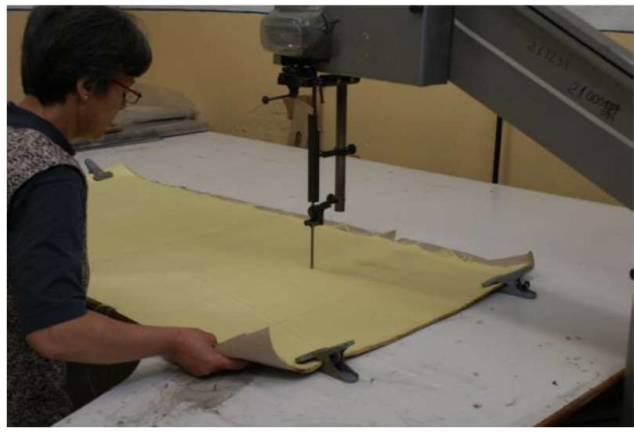

Figure 2. Cutting process of the layers for the ballistic.

After being cut, 12 layers formed a package, this number being selected by the authors after preliminary tests on 8 layers that give both results as total and partial perforation. In previous works [6, 17], macro simulation on equivalent layers gives similar results to the tested package with the same number of layers (bullet was stopped on the last broken layer for a virtual package of 8 layers and simulation on 12 layers package give 
satisfactory results, thus, this number of layers (12) was used in forming a protective package.

The projectile was a FMJ (Full Metal Jacket). $9 \mathrm{~mm}$ bullet, as required for protection level IIA as given in NIJ Standard-0101.06/2008 [23]. The layers were laterally fixed by sewing on two sides, on a central location for a length of approx. $90 \mathrm{~mm}$, in order to maintain its integrity and the layers' order. The packages were tested using ballistic barrel, the measured velocity of the projectiles being $420 \mathrm{~m} / \mathrm{s} \pm 10 \mathrm{~m} / \mathrm{s}$ ).

\section{Ballistic impact testing}

In practice, in order to assess the impact resistance of a protection system, there are reference standards that propose methods of assessment, such as NIJ Standard0101.06/2008 [23] and NIJ 0101.04/2004 [22], the results giving the possibility to include the system in a level of protection [10].

The assessment of the ballistic resistance of the studied protection packages was performed according to NIJ 0101.04 / 2004 [22], by firing with a $9 \mathrm{~mm}$ caliber bullet, with an initial speed of $420 \mathrm{~m} / \mathrm{s} \pm 10 \mathrm{~m} / \mathrm{s}$, from a distance of $3 \mathrm{~m}$ (normal conditions), shots done in a laboratory facility (Figure 3).

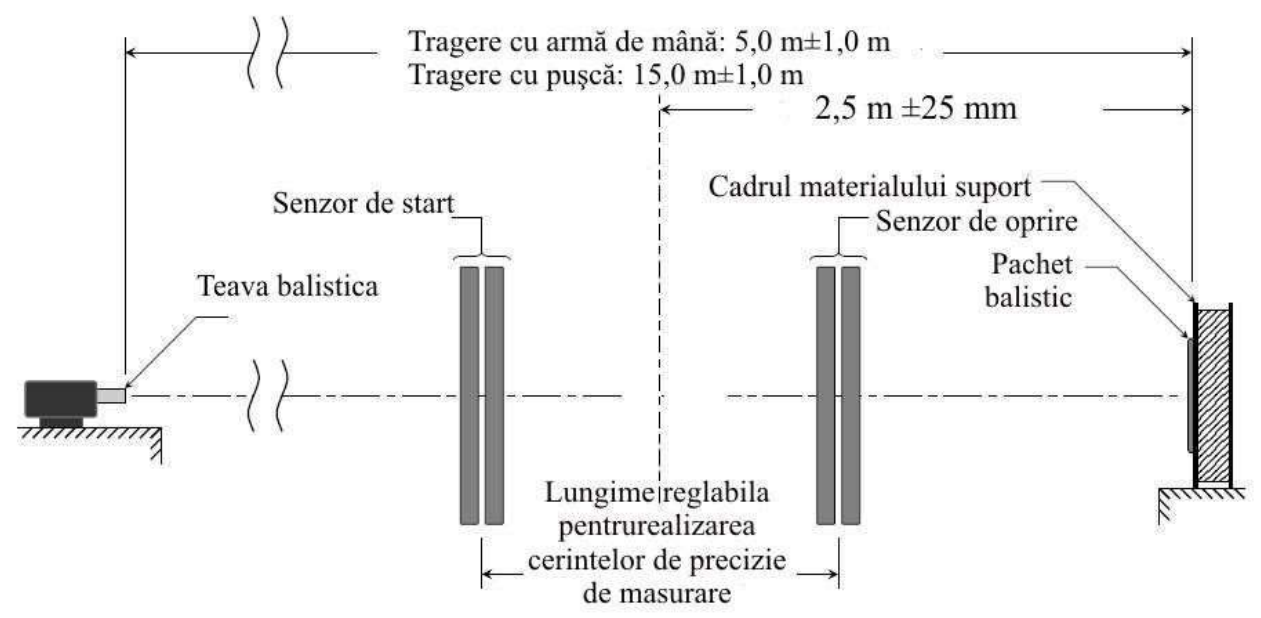

Figure 3. Fire arrangement equipment [23].

The testing of the realized protection packages in order to evaluate their resistance to the $9 \mathrm{~mm}$ FMJ bullet was discussed taking into account the resistance to penetration through the depth of the trace left in the support material (ballistic clay), namely Back Face Signature (BFS). The assessment of the total penetration of a package is in many cases simple, when it is found that there is a hole with a diameter at least equal to the caliber of the bullet and that the entire bullet passes through it.

When testing personal ballistic protection equipment, the trauma on the human body is assessed by the depth of the BFS imprint that is formed in the ballistic clay on which the sample is fixed. The standard admits as satisfactory materials and equipment, which produces an imprint in the support clay that does not exceed $44 \mathrm{~mm}$ [23].

The following steps are performed when testing personal armors or parts of it:

- the test equipment is positioned in the clamping support, at the distance imposed for each equipment from the mouth of the barrel; the types of weapons and ammunition required for levels II and IIA are verified [23];

- $\quad$ positioning of the bullet speed measurement system, starting with the distance of 2 $\mathrm{m}$ from the mouth of the barrel, so that the frames of the system are in planes 
perpendicular to the firing direction; the distance between the frames of the system is $0.5 \mathrm{~m}$; the distances are measured with an accuracy of $1 \mathrm{~mm}$;

- $\quad$ fire is executed on the test package.

\section{Results and discussion of failure mechanisms}

Factors influencing the ballistic protection against a specified threat includes those characterizing the target material(s), in terms of fiber and yarn properties, weave architecture, surface density and number of plies, boundary conditions and those characterizing the impact (impact velocity, impact angle, projectile shape and materials etc.) [10].

How to evaluate the ballistic response of a body armor? The evident investigation is at macro scale and the tests will be of clear results: the target resisted or not, the backface signature could reveal the degree of protection and the residual velocity would indicate how faraway is the protective solution, but in a qualitative way. But this scale does not offer answers to improve the ballistic resistance and the study of how projectile and target are destroyed at lower scale is of great interest. Thus, researchers will investigate the target and projectile failure mechanisms using optical and scanning electron microscopes, high speed camera, spectrometers etc.

A synthesis of the damage mechanisms under impact is given in Figure 4.

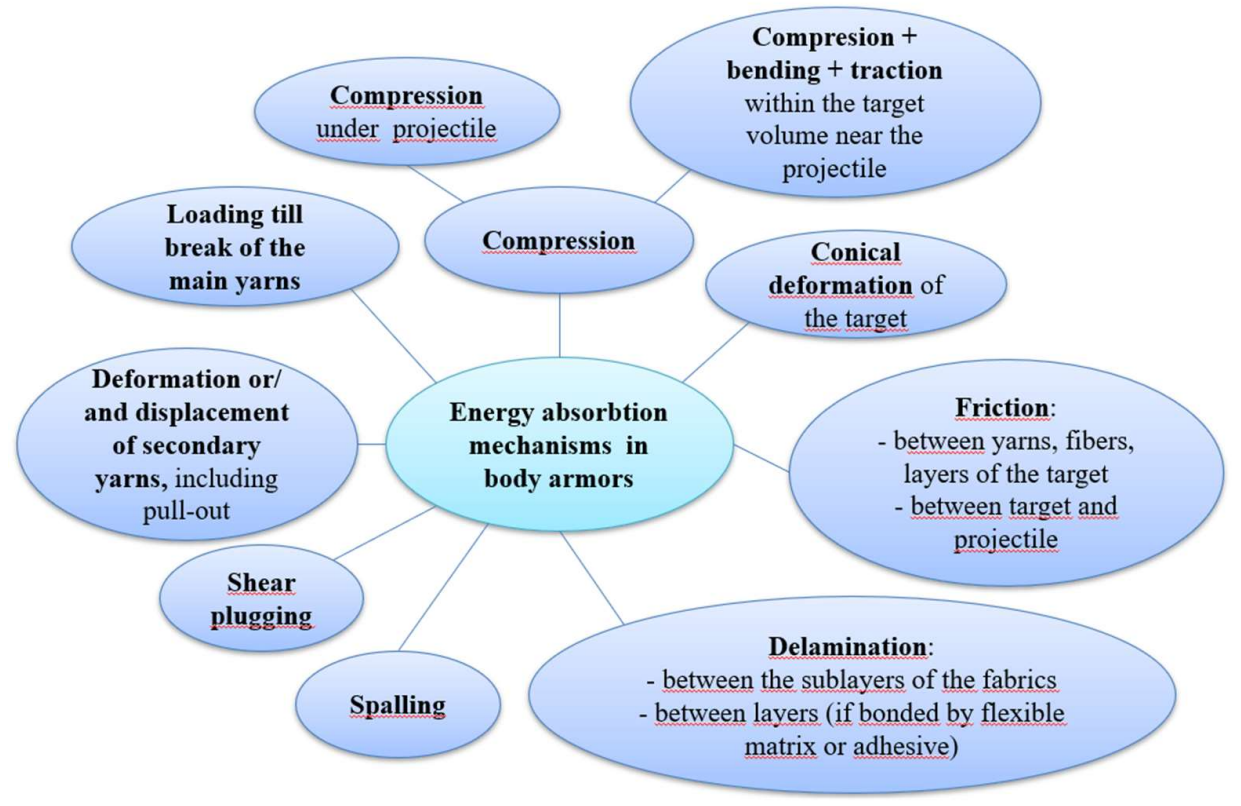

Figure 4. Damage mechanisms for packages based on fabrics.

Based on a general overview [10, 24] on how kinetic energy of the projectile is absorbed, this study aims to identify damage mechanisms for a particular package of 12 layers of LFT SB1plus when impacted with a 9 mm FMJ:

- compression of the package directly under the bullet First bullet;

- compression in the target volume surrounding the impacted zone;

- $\quad$ conical deformation on the package back face;

- loading the main yarns which face the higher strain,these yarns tend to fail when the induced tensile strain of these yarns exceeds the ultimate strain;

- deformation and/or displacement of secondary yarns;

- delamination especially on the layers situated towards the back of the target; 
- shear plugging;

- $\quad$ spalling of the layers (yarns) already broken;

- friction between the projectile and the target and friction between yarns and layers.

The secondary yarns are close to the main ones, absorbing energy by their strain distribution within the yarns and highest values are found near the top face of the deformed cone.

As friction coefficient is difficult to be measured for high impact velocities, simulation offers a fair evaluation by scanning a large range of fricion coeffoicient. Friction coefficient could have lower values, more intense being when the bullet is forced to be deformed inside the target.

When the bullet hits the target, because of the sudden drop in contact force, only the upper few layers fails by shear as the shear wave propagates along the thickness direction. Then, the undamaged layer absorbs the residual kinetic energy of the projectile through creating a cone-shaped deformation. For woven fabrics this deformation could be romboidal, the romb diagonals being almost oriented along the warp and weft?? yarns. The multi-axial unidirectional fabrics have an intermediate behavior, that is the shape of deformation could be almost conical.

Shear plugging is one of the major damage modes while impact for energy absorptions by the targets. This phenomenon is occurred due to the immediate impact contact force between the projectile and the target results in through the- thickness shear plugging stress within the target around the periphery of the projectile. If shear plugging stress exceeds the ultimate shear plugging strength, the target would fail. The failure by shear plugging is not simmetrical as if the first yarns will be broken my shear, these yarns are de-stressed and able to be displaced when the projectile advances.

During an experimental campaign, the investigation of failure mechanisms point out the ballistic performance of a specific target configuration when hitted by different projectiles, with different impact velocities.

The test results from 9 fires on three packages made of 12 layers of SB1plus are plotted in Figure 5, on a web chart, red line being the accepted limit of $44 \mathrm{~m}$ [23] and the blue points are the values measured as depth of the imprint in the ballistic clay. Figure 6 presents the shape, as taken with a mold resin, produced by a fire in the ballistic clay behind the package in order to heighlight the importance of this characteristic for body armor. From this study, the authors want to suggest a more detail evaluation of the entire shape of the backface signature, not only its depth in the ballistic clay, here BFS being of $18 \mathrm{~mm}$.

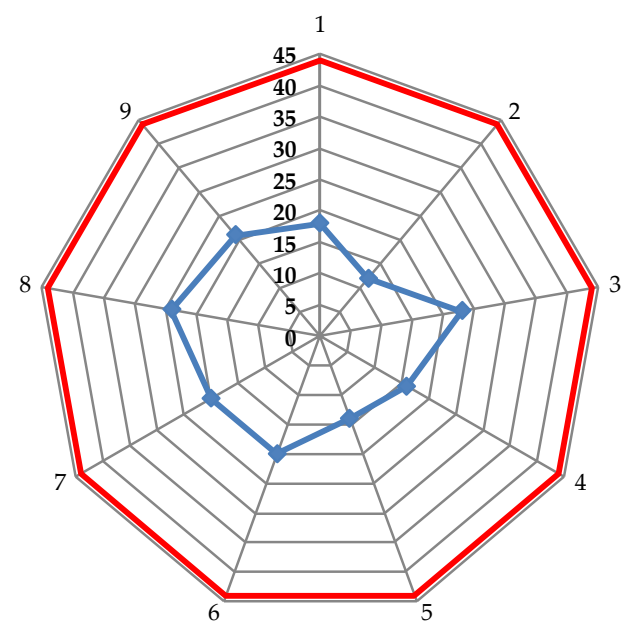

Figure 5. Data for BFS measured for 9 fires on three packages made of 12 layers of fabrics SB1plus. 


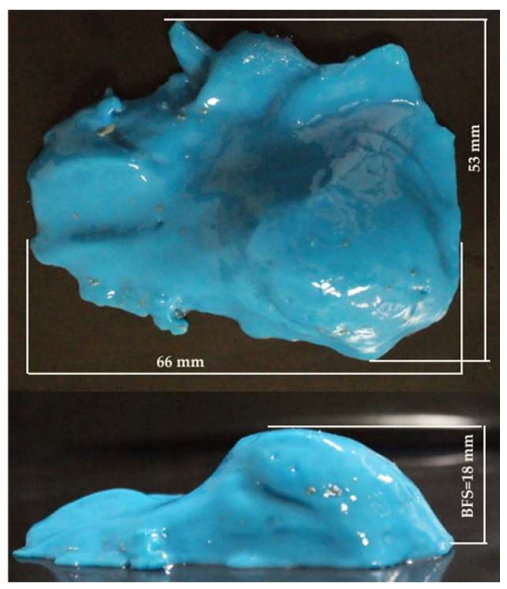

Figure 6. Cavity shape in the ballistic clay, obtained with a molding resin.

An investigation of the destruction of flexible packages was carried out with the help of a professional camera to highlight characteristics dependent on fabrics architecture and the number of layers. A detailed, photographic study on each layer of the tested ballistic packages was performed to highlight the failure processes in stages of the layers.

Figures 7-11 show photographs of LFT SB1plus layers from a 12-layer package. It should be noted that the tests were performed under conditions of a small variation for the bullet velocity $(410 \ldots 430 \mathrm{~m} / \mathrm{s})$. The angle of impact is normal on the target surface, the deviations being $5 \%$ at the mouth of the barrel.

In the details of the photos, for each shot the main wires (broken) and the secondary wires (those affected by the penetration of the projectile, by twisting, firing, scattering) may be counted.

In Figures 7 and 8, one may see the total penetration of the first layers in the designed ballistic package and it is highlighted the localized rupture of the yarn. This type of failure occurs when all the fibers of the thread break in almost the same place. The two causes of the breaking of the yarns in layer 1 are their stretching along the length next to the contact with the projectile and the shearing on their thickness, observed in Figure 7 (detail b). Theoretically, the fibers in the yarn will fail when the induced strain exceeds the strain at break, but the process is dynamic (depending on strain rate) and statistic, given the large number of fibers in a yarn.

Starting from layer 3 (Figure 9) and in layer 4 (Figure 10), the enlargement of the holes is observed (due to the lateral plastic deformation of the projectile when it starts to be stopped), and also the process of pulling the threads. The tear-off of the yarn (even partially) from its fabric architecture occurs when the yarns are not broken, sometimes only one side of the projectile. The force required to pull out the yarn from the net has to be theoretically equal or greater than the frictional force on the contact among the yarns in question and the other perpendicular yarns in the next layer (SB1plus being composed by 4 four sublayers with unidirectional yarns in a $\left(0^{\circ}, 90^{\circ}, 45^{\circ},-45^{\circ}\right)$ arrangement, and because of the projectile, which deformed and broken at the edge, hangs part or all of the yarn [6].

Layer 4 is the last layer in the SB1plus LFT package through which the bullets passed or stopped. In the current case of failure, the first 4 layers have the role of slowing down, even arresting and deforming the projectile. 


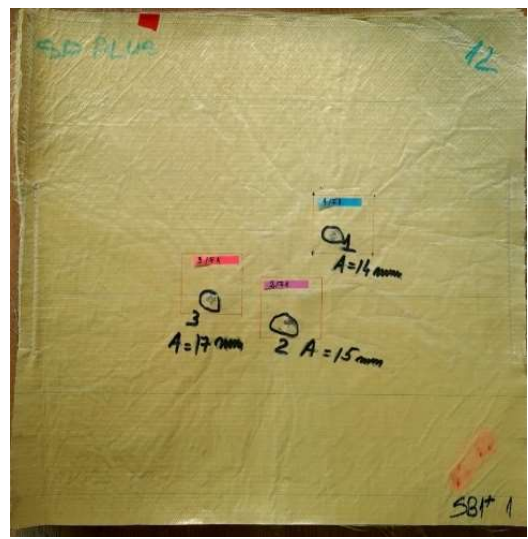

(a)

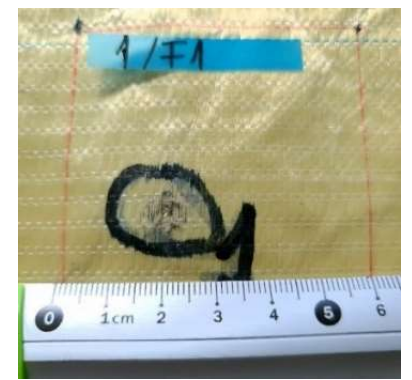

(b)

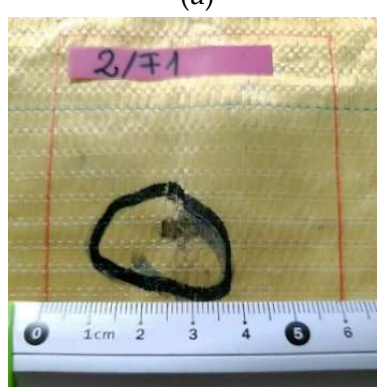

(c)

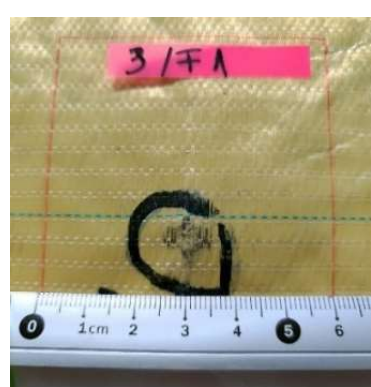

(d)

Figure 7. Frontal view (a) of a 12 layers LFT SB1plus package: (a) layer 1 (face) and details of the fires on the first layer of the package: (b) fire 1, (c) fire 2 and (d) fire 3. BFS was noted A on the photo.

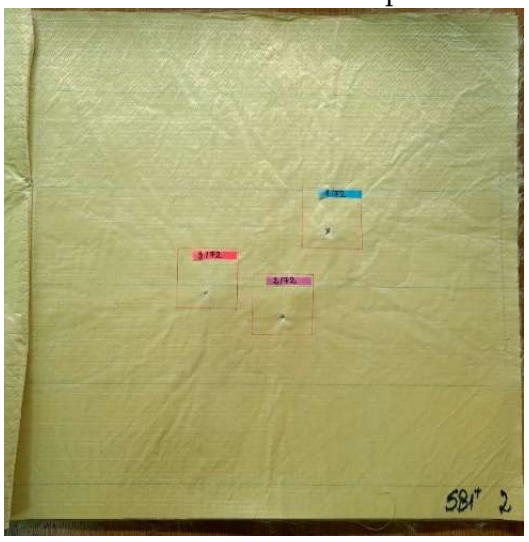

(a)

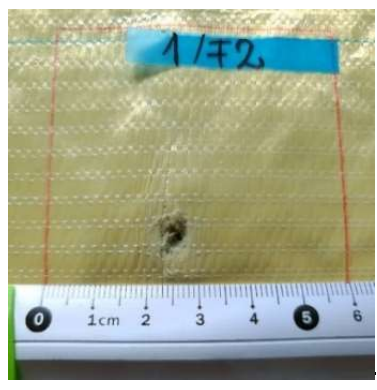

(a)

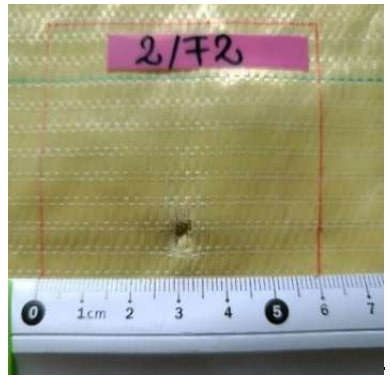

(b)

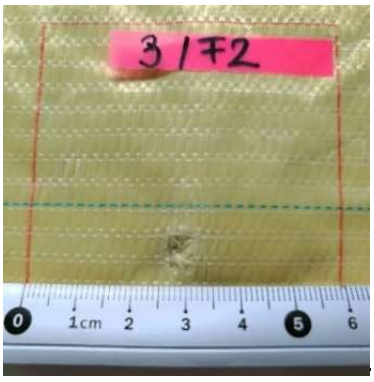

(c)

Figure 8. Frontal view of the sample with 12 layers LFT SB1plus, (a) layer 2 (face), with details of the fire hole (b) fire 1, (c) fire 2 and (d) fire 3. 
Starting from layer 3 (Figure 9) and in layer 4 (Figure 10), the widening of the holes is observed (due to the lateral deformation of the projectile when it starts to be stopped, and the process of pulling the wires.

The fibrillation at the broken ends of the yarns (Figure 7) or along the yarn (Figure 8) is a type of failure favored by the abrasive action along the length of the fibber, but it is also dependent on the local traction characteristics of the yarn fibers. Of course, the location of the fibrillation is a defect of the molecular chains or their arrangement in the fibber. In layered systems, friction between layers results in abrasion friction among fibbers, inducing local scratches that diminish the fibber resistance. All projectiles that have the ability to penetrate through the fabric, also cause scratching and/or splitting of the fibers that favor the appearance of fibrillation, a specific failure of the aramid fibbers.

The quality of the material SB1plus is noticed by the high degree of resemblance of the penetration zones and even by the size of zones with broken and torn-off yarns.

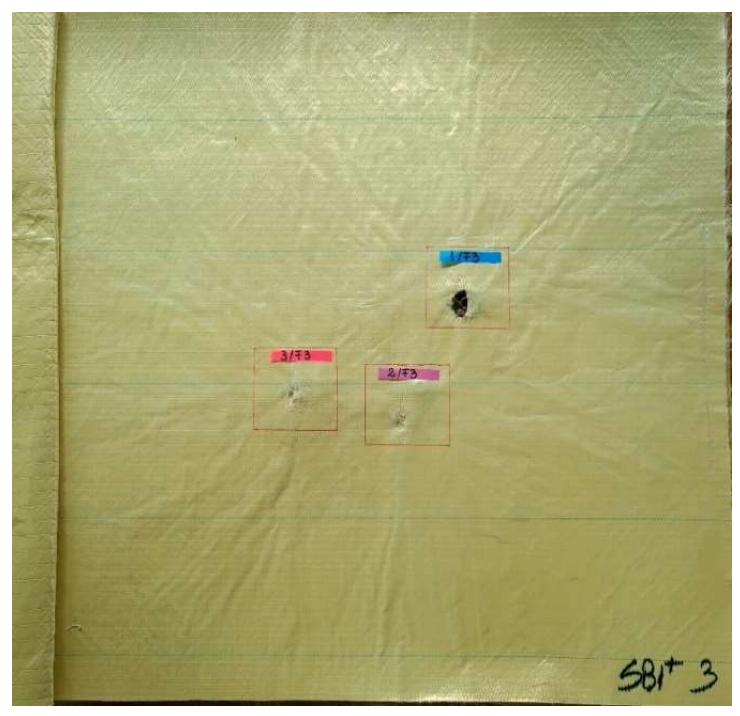

(a)

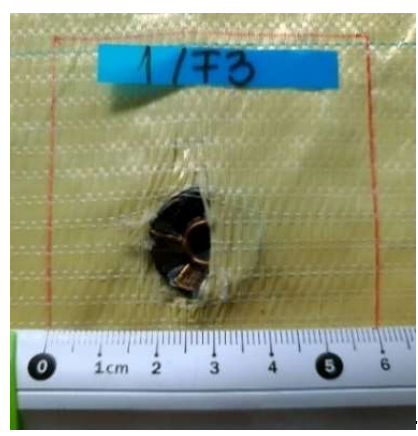

(b)

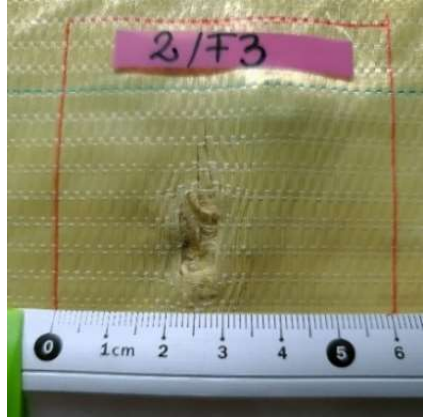

(c)

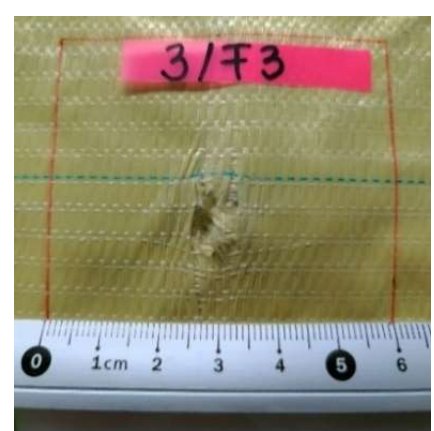

(d)

Figure 9. Frontal view of the sample with 12 layers LFT SB1plus, (a) layer 3 (face), with details of the fire hole (b) fire 1 , (c) fire 2 and (d) fire 3 .

Layer 5 (Figure 11) shows traces of crushing (compression), circular in shape, which would be justified by the architecture of the LFT SB1plus semi-finished product (with the orientation of the wires $0^{\circ} / 90^{\circ} / 45^{\circ} /-45^{\circ}$ ), inducing a tendency to uniformity of the properties of the fabrics in 4 sub-layers and, therefore, of its answer.

Layers 6 and 7, theoretically, have the role of retaining (arresting) the projectile and dumping its tendency to advance together with the fabrics. These layers and the following ones are also responsible of reducing the BFS. 


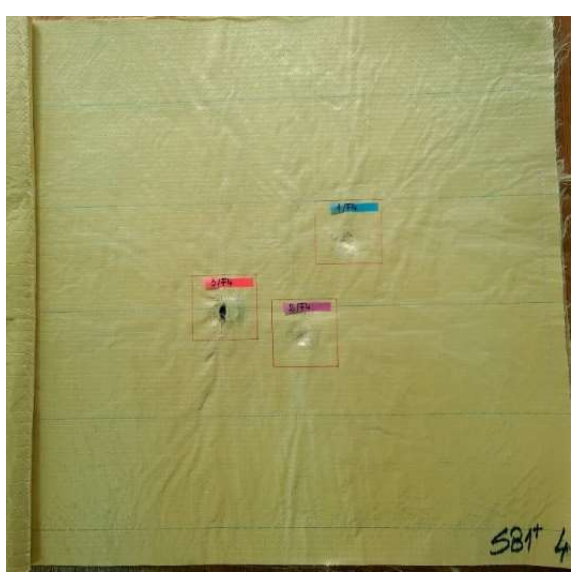

(a)

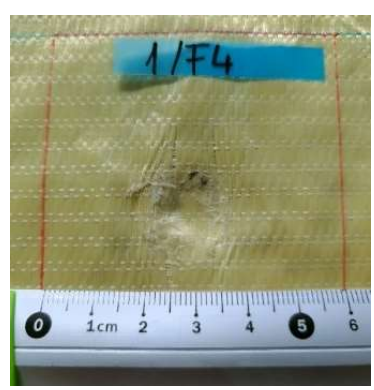

(b)

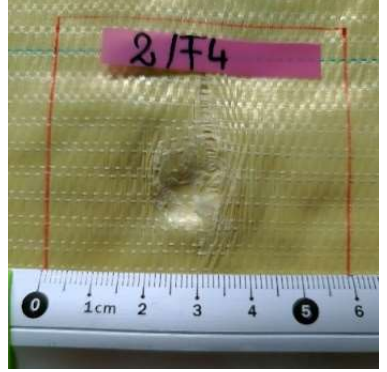

(c)

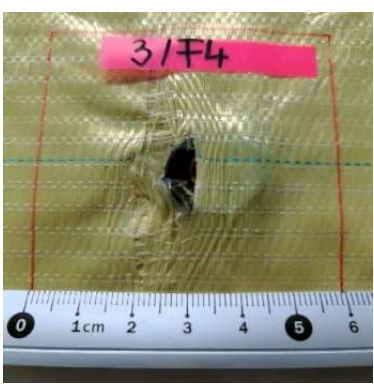

(d)

Figure 10. Front view, sample made of LFT SB1plus: (a) layer 4 (face), with detail of the penetration: (b) fire 1; (c) fire 2; (d) fire 3.

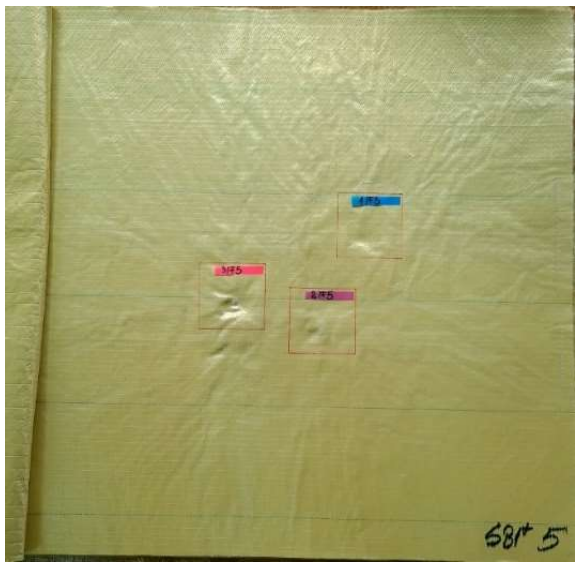

(a)

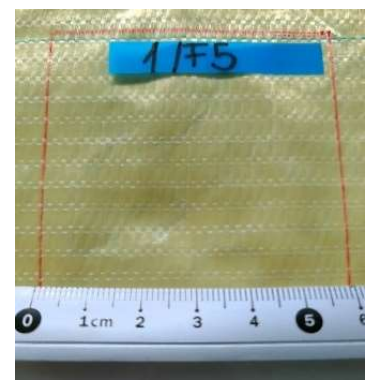

(a)

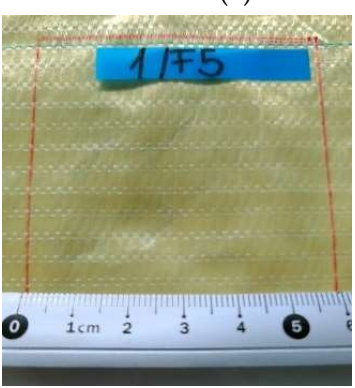

(b)

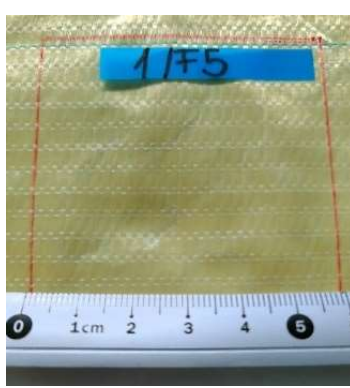

(c)

Figure 11. Frontal view of a package made of layers LFT SB1plus, (a) layer 5 (face), with details (b) fire 1, (b) fire 2, (c) fire 3. 


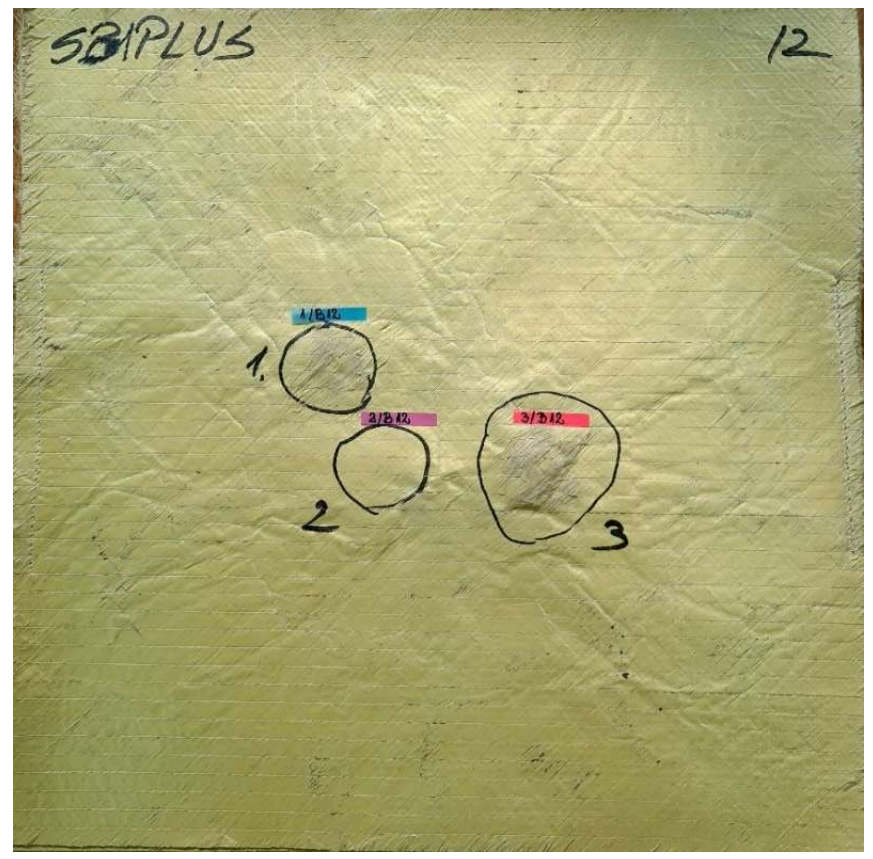

(a)

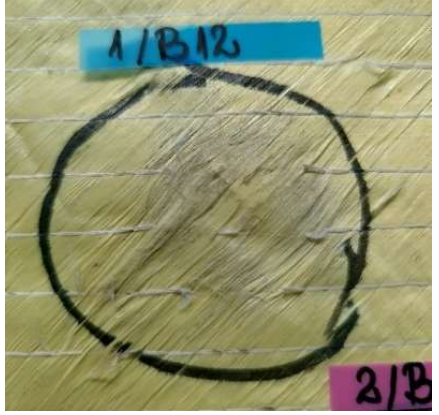

(b)

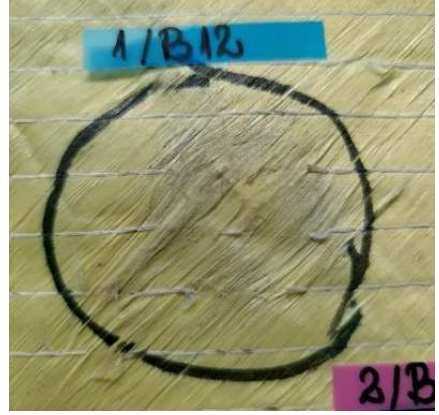

(c)

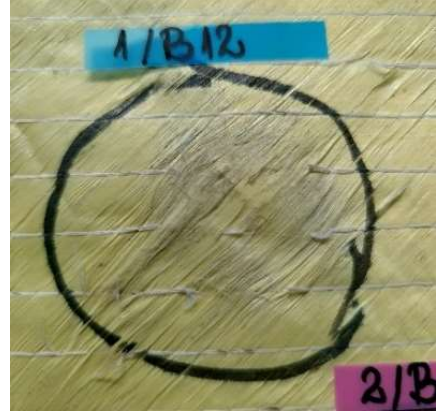

(d)

Figure 12. Back view of package made of 12 layers of LFT SB1plus: (a) layer 12 (back), with details (b) fire 1, (c) fire 2, (d) fire 3.

After testing, it can be seen that the arching in the orthogonal yarns is more dominant in the back layers of the multilayer package, where the projectile tries to enter through an edge-like approach after being considerably slowed down by the initial layers [8]. The existence of the phenomenon of passing through the fabrics usually produces a hole smaller than the diameter of the projectile, a smaller number of yarns being broken as compared to the number of yarns that intersect the projectile.

In Figure 13 a) two broken main yarns can be observed on the first layer of unidirectional yarns. The ends of the broken yarns relax after being tensioned and, hence, the appearance of scattered fibers. Figure $13 \mathrm{~b}$ ) shows the deviation of the secondary yarns from layers 2 (from the 4 substrates of a layer) and a more disordered aspect of the fibers, as compared to layer 1 .

Some particular aspects of the failure of aramid fibers could be highlighted with the help of SEM images, for the ballistic package of 12 states tested. According to SEM images, breaking a fiber can be done by shearing (Figure 15), fibrillation (Figure 14), necking (obviously, tensile stress) (Figure 15 detail (c and d) and twisting. 


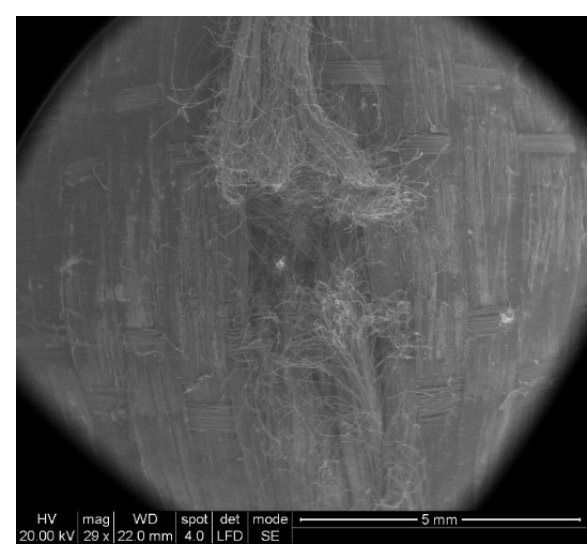

(a)

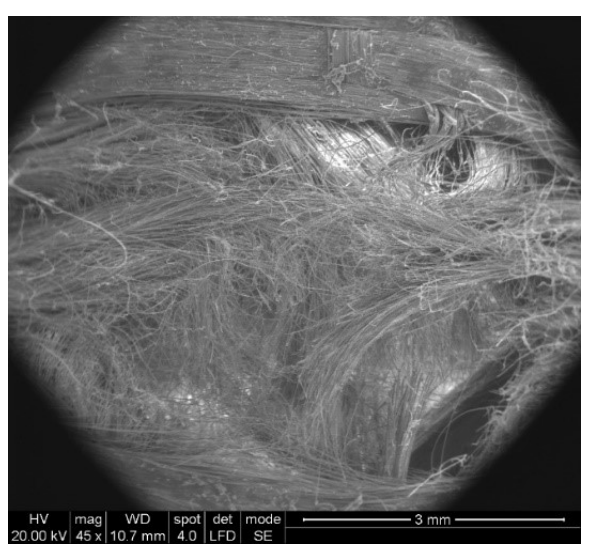

(b)

Figure 13. Aspect of broken yarns from the ballistic protection package made of LFT SB1plus. (a) face of layer 1 (fire 1); (b) face of layer 2 (fire 1)

In Figure 14, by the help of scanning electron microscopy, one may see the fibrillation, thinning and rupture of the aramid fibrils, resulting from the process of destroying a thread on the 2nd layer.

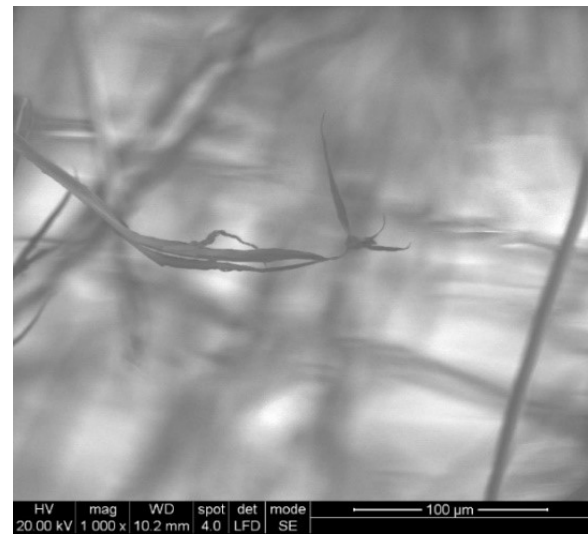

(a)

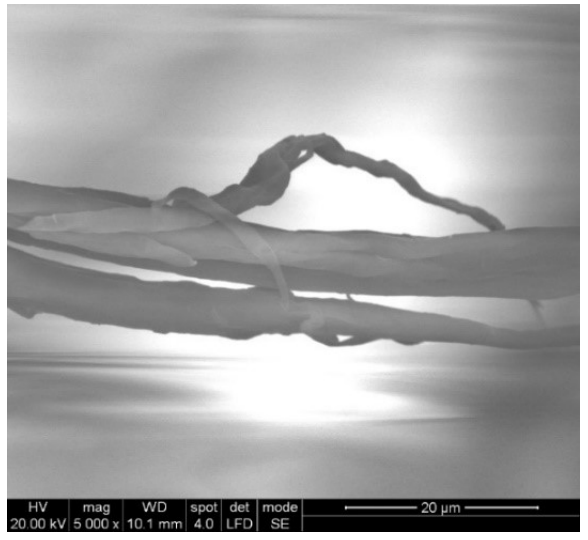

(b)

Figure 14. Details of fibres from the ballistic package LFT SB1plus. (a) fibril from front layer 2; (b) detail from (a).

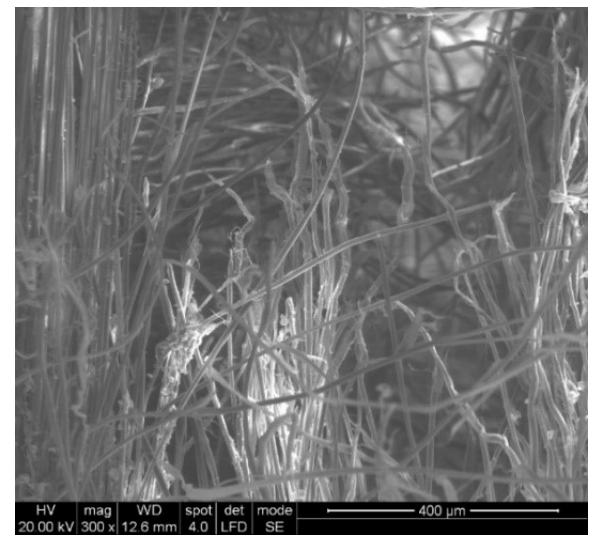

(a)

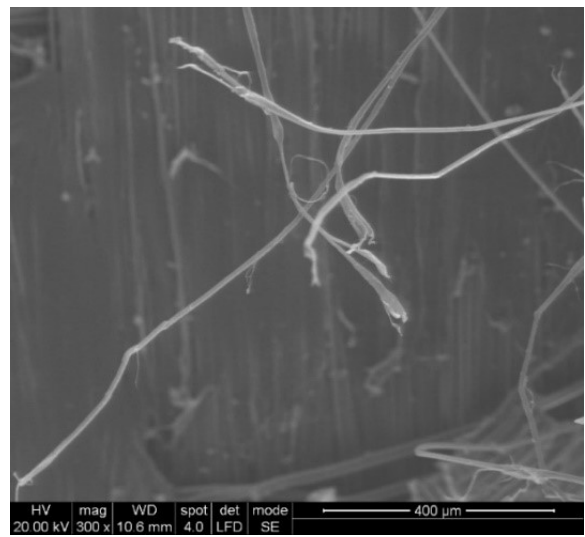

(b) 


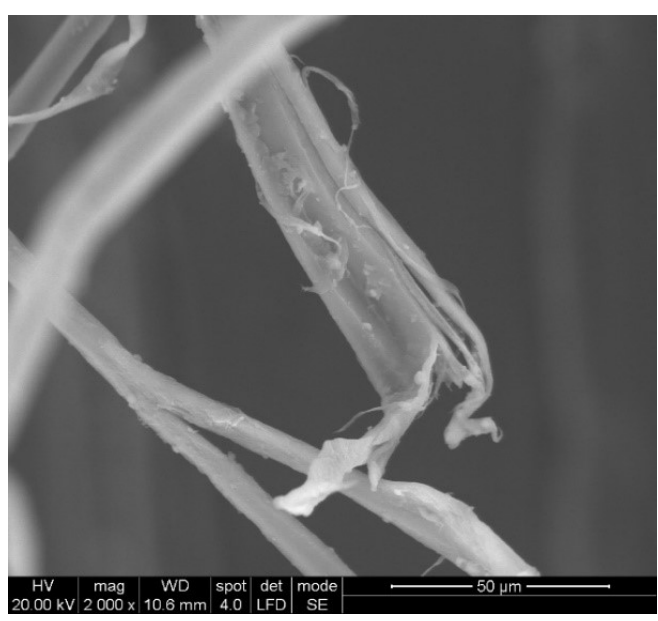

(c)

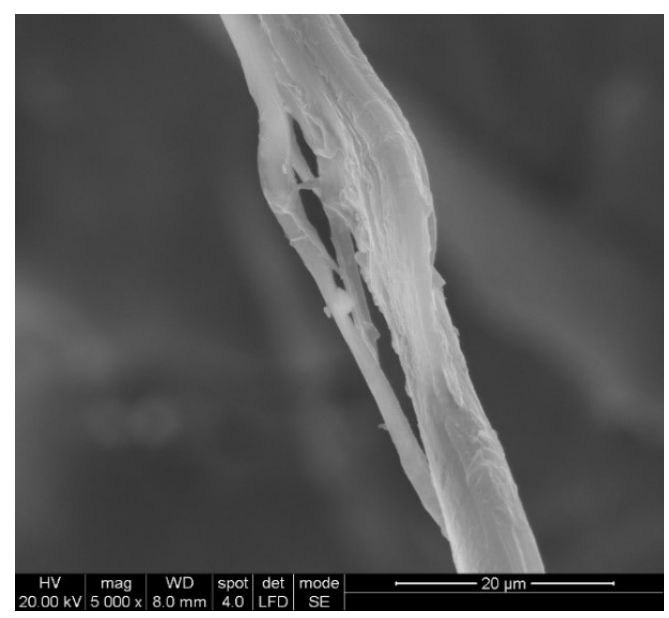

(d)

Figure 15. Details of the broken fibrils from the 2nd layer of the LFT SB1plus ballistic package. (a) layer 1, front view of the broken fibers 2; (b) detail of Layer 1, front view of the broken fibers; (c) detail of a higher magnification of a fiber; (d) detail of (b) with nonuniform fibrilation and necking.

The values for BFS (back face signature) for the LFT SB1 plus package are given in Table 1 and are measured according to Ballistic Resistance of Body Armor, NIJ Standard0101.06 [2] (see also Figure 3).

Figure 15 shows the detail of some fibers damaged by fibrillation and discontinuities are observed in the fibber and a thinning of the thicker fibril that supported the load and the rupture of fibrils resulting from tensile and shearing (short, undeformed break as a cut) following the destruction process. This section may be divided by subheadings. It should provide a concise and precise description of the experimental results, their interpretation, as well as the experimental conclusions that can be drawn.

Table 1. BFS of a ballistic package made of LFT SB1plus layers.

\begin{tabular}{cc}
\hline \multicolumn{2}{c}{ LFT SB1 plus, package of 12 layers } \\
\hline Fire & BSF [mm] \\
\hline 1 & 14 \\
2 & 15 \\
3 & 17 \\
\hline
\end{tabular}

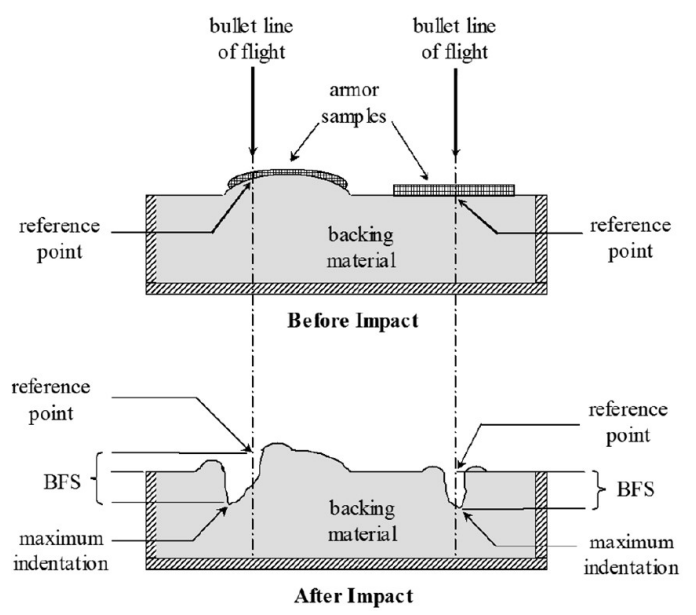

Figure 16. Measuring BFS in agreement with Ballistic Resistance of Body Armor, NIJ Standard0101.06 [23]. 
Imprints in the clay support material, measured as BFS test for a new armor package, are analyzed to determine whether the armor will provide adequate protection against trauma (without perforation / penetration of the package). The requirements of the NIJ [23] state that all depths of the measured traces in the support material obtained from fire falling within the firing requirements must not exceed $44 \mathrm{~mm}$ or be less, or if the BFS exceeds $44 \mathrm{~mm}$ then there must be a coefficient of $95 \%$ confidence that $80 \%$ of the depths of the traces in the support material will be $44 \mathrm{~mm}$ or less. Under no circumstances should a trace in the support material exceed $50 \mathrm{~mm}$.

Measured BFSs for a new armor package are analyzed to determine whether the armor will provide adequate protection against trauma (without perforation/penetration of the package). The requirements of the NIJ [23] state that all depths of BFS in the support clay, obtained from fires obeying the firing requirements, must not exceed $44 \mathrm{~mm}$ or be less, or if the BFS exceeds $44 \mathrm{~mm}$ then there must be a coefficient of $95 \%$ confidence that $80 \%$ of the depths of the imprints in the support material will be $44 \mathrm{~mm}$ or less. Under no circumstances should a BFS in the support material exceed $50 \mathrm{~mm}$.

Following the extraction of the bullets from a package of 12 LFT SB1 plus layers, the following characteristics of the recovered projectiles could be highlighted based on the analyzes of the photographs in figure 17:

- bullets are flatted as a mushroom cap;

- bullets have initiated fragmentation on their edges, but no fragments seem to be separated, with jacket and core torn off Second bullet;

- their faces in contact with the target have trapped aramid fibbers, especially from the first and second hit yarns.

The number of layers penetrated in the package influences the way the projectile is damaged, the bullets retained within the package (Figure 17) have a very flattened shape, with peripheral ruptures of the jacket and core.

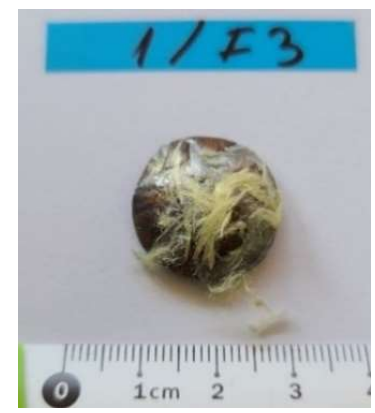

(a)

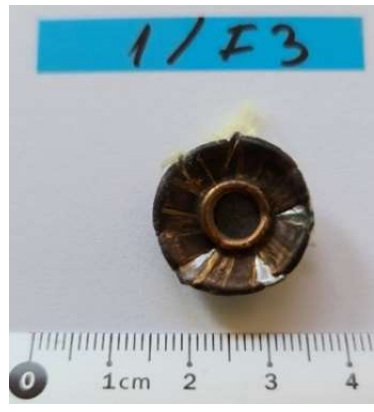

(a)

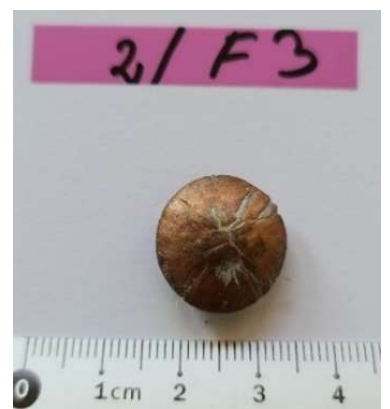

(b)

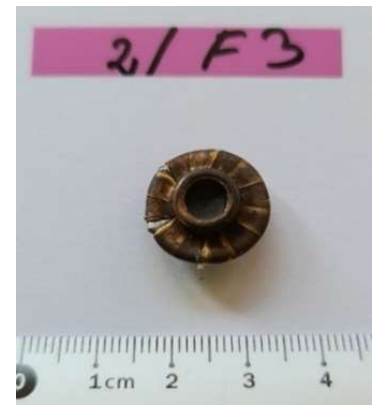

(b)

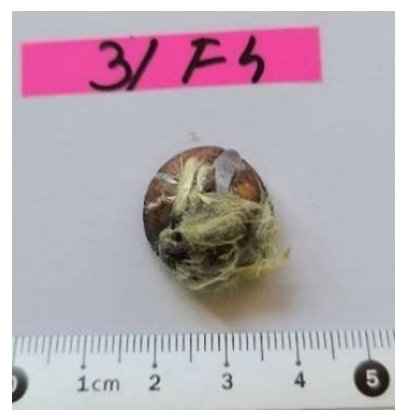

(c)

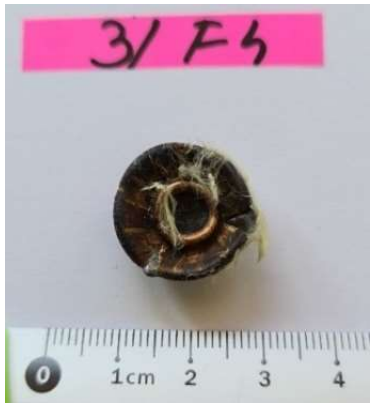

(c)

Figure 17. Bullets $9 \mathrm{~mm}$ FMJ as recovered after testing 12-layer ballistic package: front view of the bullets (a), (b) and (c); back view of the same bullets (d), (e) and (f). 
Figure 18 presents details of the impacted face of the projectile, after testing. One may notice the embedding of fragmented aramid yarns on the projectile front. The first yarn contacting the bullet was broken near its contacting length with the bullet, due to high tensile stress; this central fragment is so compressed that its fibbers are forced into the projectile material and remained fixed on the bullet, even if this one is intensively deformed and cracked. The bullet from 3rd fire kept the similar aspect of the bullet failure (local fragmentation and plastic deformation, but the fibbers are only several "sticked" to the bullet. Several fibbers are trapped in the cracks of the projectile, both in the lead core and copper alloy jacket.

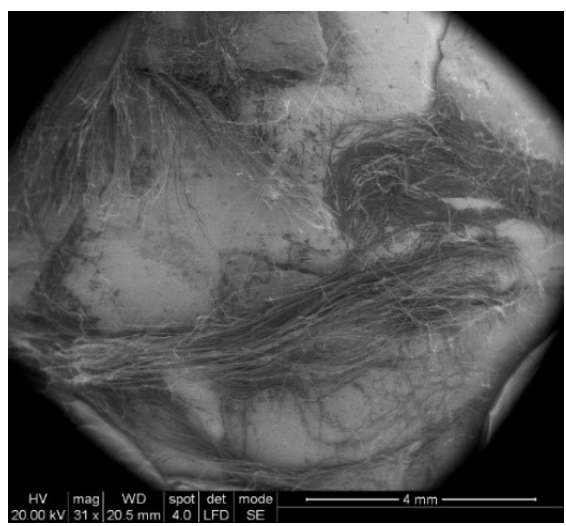

(a)

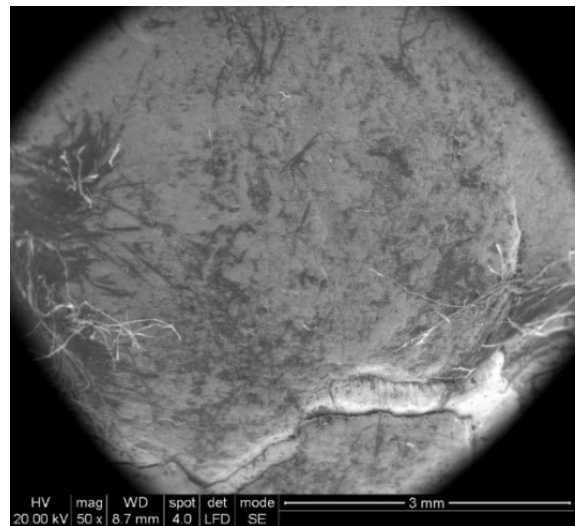

(b)

Figure 18. SEM details of bullet of $9 \mathrm{~mm}$ FMJ, as retrieved after fire. (a) bullet of 2nd fire; (b) bullet of 3rd fire.

\section{Discussion}

Authors should discuss the results and how they can be interpreted from the perspective of previous studies and of the working hypotheses. The findings and their implications should be discussed in the broadest context possible. Future research directions may also be highlighted.

\section{Conclusions}

The main objective of this study focuses on designing and testing protection systems using advanced materials based on aramid fibers for high impact speeds of up to $410 \ldots 430$ $\mathrm{m} / \mathrm{s}$. The investigation of the failure mechanisms identifies current issues of protective materials, major challenges and technological problems for developing these types of systems, including the fulfilling of ballistic impact requirements according to NIJ Standard-0101.06 [23].

The purpose of the paper was to do an investigation on the failure processes and destructive stages of a ballistic package made of successive layers of LFT SB1plus, taking into account the particular test conditions from NIJ Standard-0101.06 [23]. The main parameter of interest was the backface signature (BFS), but also details of projectile arrest and SEM investigation could offer argument in using this material for individual protection.

Author Contributions: For research articles with several authors, a short paragraph specifying their individual contributions must be provided. The following statements should be used “Conceptualization, C.P. and L.D.; methodology, C.P. and L.D.; software, C.P.; validation, L.D.; formal analysis, C.P.; investigation, C.P.; resources, C.P.; data curation, L.D.; writing-original draft preparation, C.P.; writing - review and editing, L.D.; visualization, C.P.; supervision, L.D.; project administration, C.P.; funding acquisition, C.P. All authors have read and agreed to the published version of the manuscript." 
Funding: This research was funded by National Institute of Aerospace Research "Elie Carafoli" INCAS, Bucharest.

Acknowledgments: We acknowledge the support in test campaign, given by CBRN Defense and Ecology Scientific Research Centre, Bucharest, Romania.

Conflicts of Interest: The authors declare no conflict of interest.

\section{References}

1. Claus, J.; Santos, R. A.M.; Gorbatikh, L.; Swolfs, Y. Effect of matrix and fibre type on the impact resistance of woven composites, Composites Part B, 2020, 183 107736, https://doi.org/10.1016/j.compositesb.2019.107736.

2. Abtew, M. A.; Boussu, F.; Bruniaux, P.; and Liu, H. Fabrication and Mechanical Characterization of Dry Three-Dimensional Warp Interlock Para-Aramid Woven Fabrics: Experimental Methods toward Applications in Composite Reinforcement and Soft Body Armor, Materials 2020, 13, 4233; doi:10.3390/ma13194233.

3. Bhatnagar, A. Lightweight ballistic composites, CRC Press, Boca Raton Boston New York, 2006.

4. Termonia, Y. Impact Resistance of Woven Fabrics, Textile Research Journal, 2004, 748, pp. 723-729, Sage Publications.

5. Tam, D. K. Y.; Ruan, S.; Gao, P.; Yu, T. High-Performance Ballistic Protection Using Polymer Nanocomposites (Chapter 10) in Advances in Military Textiles and Personal Equipment, Woodhead Publishing Limited, 2012.

6. Pirvu, C.; Contribution on Experimental and Numerical Study of Ballistic Protection Packages Made of Aramid Fabrics, PhD thesis, “Dunarea de Jos” University, 47 Domneasca, Ro-800008, Galați, Romania, 2015.

7. Bajya, M.; Majumdar, A.; Butola, B. S.; Arora, S.; Bhattacharjee, D. Ballistic performance and failure modes of woven and unidirectional fabric based soft armour panels, Composite Structures, 2021, 255, 112941.

8. Guo, Z.; Chen, W. A merit parameter to determine the stacking order of heterogeneous diphasic soft armor systems, Composite Structures, 2020, 241, 112086, https://doi.org/10.1016/j.compstruct.2020.112086

9. Gonçalves Nunes, S.; Scazzosi, R.; Manes, A.; Campos Amico, S.; Ferreira de Amorim Jr, W.; Giglio, M. Influence of projectile and thickness on the ballistic behavior of aramid composites: Experimental and numerical study, International Journal of Impact Engineering, 2019, 132, 103307.

10. Abtew, M. A.; Boussu, F.; Bruniaux, P.; Loghin, C.; Cristian, I.; Ballistic impact mechanisms - A review on textiles and fibrereinforced composites impact responses, Composite Structures 2019, 223, 110966, https://doi.org/10.1016/j.compstruct.2019.110966

11. Naik, S.; Dandagwhal, R. D.; Loharkar, P. K.; A review on various aspects of Kevlar composites used in ballistic applications, Materials Today: Proceedings, 2020, 21,1366-1374

12. Gürgen, S. Numerical modeling of fabrics treated with multi-phase shear thickening fluids under high velocity impacts, ThinWalled Structures, 2020, 148, 106573, https://doi.org/10.1016/j.tws.2019.106573

13. Yang, Y.; Zhang, X.; Chen, X.; Min, S.; Numerical Study on the Effect of Z-Warps on the Ballistic Responses of ParaAramid 3D Angle-Interlock Fabrics, Materials, 2021, 14, 479. https://doi.org/10.3390/ma14030479

14. Sockalingam, S.; Gillespie, J.W.; Keefe, M. Role of Inelastic Transverse Compressive Behavior and Multiaxial Loading on the Transverse Impact of Kevlar KM2 Single Fiber. Fibers 2017, 5, 9. https://doi.org/10.3390/fib5010009

15. Chiper, T. L.; Ojoc, G.G.; Deleanu, L., Pîrvu, C. Simulation of impact behavior of a glass yarn_Mechanical Testing and Diagnosis ISSN 2247 - 9635, 2020 (X), Volume 1, pp. 10-17

16. Feito, N.; Loya, J. A.; Muñoz-Sánchez, A.; Das, R. Numerical Modelling of Ballistic Impact Response at Low Velocity in Aramid Fabrics, Materials 2019, 12, 2087; doi:10.3390/ma12132087.

17. Ionescu, T.F.; Pirvu, C.; Badea, S.; Georgescu, C.; Deleanu, L. The Influence of Friction Characteristics in Simulating the Impact Bullet - Stratified Materials, 15th International Conference on Tribology, Kragujevac, Serbia, 17 - 19 May 2017

18. Kedzierski, P.; Popławski, A.; Gieleta, R.; Morka, A,; Sławinski, G. Experimental and numerical investigation of fabric impact behavior. Compos Part B, 2015; 69:452-9.

19. Mou, H.; Jiang, X.; Hui, P.; Feng, Z.; Hongzhang, G. Ballistic impact tests and stacked shell simulation analysis of aramid fabric containment system, Aerospace Science and Technology, 2020, 107, 106344.

20. Ayten, A. İ.; Taşdelen, M. A.; Ekici, B. An experimental investigation on ballistic efficiency of silica-based crosslinked aerogels in aramid fabric, Ceramics International, 2020, 46, 26724-26730.

21. ${ }^{* * *}$ Ballistics Teijin Aramid, Ballistics material handbook 38-1405/2012.

22. *** Ballistic Resistance of Personal Body Armor NIJ Standard-0101.04, U.S. Department of Justice Office of Justice Programs National Institute of Justice, 2004.

23. *** Ballistic Resistance of Body Armor, NIJ Standard-0101.06, U.S. Department of Justice Office of Justice Programs National Institute of Justice, 2008.

24. Attwood, J.P.; Russell, B.P.; Wadley, H.N.G.; Deshpande, V.S. Mechanisms of the penetration of ultra-high molecular weight polyethylene composite beams, International Journal of Impact Engineering, 2016, 93, 153-165. 